\title{
Analysis of motor activity of premature newborns
}

\author{
Chuvakova Tamara ${ }^{1}$, Tortayeva Gulnar ${ }^{1}$, Sagandykova Elena ${ }^{1}$
}

${ }^{1}$ Department of neonatology, National research center for maternal and child health of the corporate fund "UMC», Astana, Kazakhstan

This work is licensed under a Creative Commons Attribution 4.0 International License
J Clin Med Kaz 2017; 3(45 Supp/ 3):39-43

Автор для корреспонденции: Чувакова Т.К., отдел неонатологии, Национальный научный центр материнства и детства корпоративного фонда «UMC» Адрес: 010000 Казахстан, г. Астана, пр. Туран 32. Телефон +7 7019996880 .

Электронный адрес:ch.tamara@mail.ru.

\section{ABSTRACT}

Objective: The article studies the clinical features of the motor system of premature newborns, a possible prognosis for development has been determined and the program of non-drug rehabilitation of children born with a burdened perinatal anamnesis has been optimized.

Methods. Observation of the movements of the child was carried out with the help of a video camera, which was installed over an incubator or crib. Video recording of the child's movements was carried out in a state of calm wakefulness, in the absence of external stimulant. Recording was interrupted for the period of feeding, sleeping, crying. For shooting and assessing the movements of a prematurely born baby, a video recording session of 30-40 minutes is required.

Results. Based on the results of the survey of 129 premature infants in the department of neonatology of the NNCMD, it was found that in children with a gestational age of 29-34 weeks, the poor repertoire is the most frequent - $41.4 \%$. Normal generalized movements and the norm option - non-optimal movements occur $22.7 \%$ and $23.5 \%$ respectively, convulsively-synchronized and chaotic movements - in $12.9 \%$. In the case of repeated studies, transitions from normal generalized movements to poor repertoire occurred in $3.2 \%$ of children, from poor repertoire to normal generalized movements in $7.4 \%$, from spasmodically synchronized to poor repertoire - in $1.6 \%$ of convulsive- synchronized into normal generalized movements - in 1.9\%. At the age of 3-5 months of life, all children with poor repertoire formed normal type of movements, and of 40 children with convulsively synchronized and chaotic movements, in $5(1.6 \%)$ tetra paresis was diagnosed, which does not exclude the subsequent realization in these children Cerebral palsy.

Conclusions. The clinical features of the motor system of premature newborns study determined a possible developmental prognosis, which facilitated an optimized program of non-drug rehabilitation of children born with a burdened perinatal anamnesis.

A clinical evaluation of premature babies on the basis of the results of developing care showed that in PKV 33 weeks, $70 \%$ of the children who were on probing, on average, after 6 days switched to feeding with a cup and $40 \%$ of children already fed from a cup - 5-6 day began to suck the mother's breast.

All children had a stable weight gain. $80 \%$ of children had a deeper and more restful sleep. When carrying out painful manipulations, all children had a lower pain threshold. Stabilization of behavior was observed.

At 35 weeks of PKV, $70 \%$ of the children switched from breastfeeding to feeding, the rest of the children were breastfeeding. All the children were transferred to nursing in a crib. All infants had a positive emotional tone. Against basal stimulation, visual concentration improved. Tactile stimulation of the palms and palms allowed to form a correct thumb installation in the cam and improved their psychomotor development.

Key words: premature infants, motor activity, Prechtl method. 
ТҰЖЫРЫМДАМА

ШАЛА ТУҒАН НӘРЕСТЕЛЕР ДЕНЕ БІТІМІНІҢ ҚОЗҒАЛУ САРАПТАМАСЫ.

Чувакова Т.К.' ${ }^{1}$ Тортаева Г.С. ${ }^{1}$, Сагандыкова Е.С. ${ }^{1}$

'Неонатология бөлімі, «UMC» корпоративтік қорының Ана мен бала ұлттық ғылыми орталығы, Астана, Қазақстан

Зерттеудің мақсаты. Статьяда шала туған нәрестелердің дене бітімі қозғалысы туралы зерттеу жұмыстары нәтижесі анықталған. Яғни шала туған нәрестелерді дәрі дәрмексіз жетілдіруге, ем шара жүргізуге болатын программа көрсетілген.

Әдістері. Баланың қозғалысын қадағалау кувез немесе кроватта орнатылған бейне камераның көмегімен жүзеге асырылды. Бейнежазба баланың қозғалысы тыныштық жағдайында және сыртқы орта кедерісінсіз жүзеге асырылды. Жазу тамақтану, ұйықтау, жылау кезеңінде тоқтатылып отырды. Мерзімінен бұрын туылған баланың қозғалысын түсіру үшін ұзақтығы 30-40 минут бейнежазба сеансы қажет.

Нәтижелері. Тексерулердің нәтижесі бойынша 129 шала туған нәрестелердің, неонатология бөлімінде ННЦМД-да өткізілген, гестациялық жасы 29-34 апталық балалар төменгі нәжилер көрсетті 41,4\%. Қалыпты жалпыланған қозғалыстар және норма - оңтайлы емес қозғалыстардың тиісінше 22,7\% және 23,5\%, синхрондалған-тырысулар және хаотикалық қозғалыстар - 12,9\%. Қайталанылған сынақтар нәтижесінде қалыптыдан генерализденген қозғалыстар төменгі нәтижелер балалардың 3,2\%, ал төменгі нәтижелер қалыпты қозғалыста 7,4\% деңгейінде, синхрондалған-тырысулар төменгі нәтижесі 1,6\%, синхрондалған-тырысулардан орын алған қалыпты жалпыланған қозғалыстарға - 1,9\%. Өмірінің 3-5 айында, төменгі нәтиже көрсеткен барлық балаларда қалыпты қозғалыс қалыптасты, ал 40 бала ішінде синхрондалған-тырысулар және хаотикалық қозғалыстармен, 5 (1,6\%) диагноз тетрапарез анықталып, болашаұта осы балаларда Церебралды шалдығуға ұшырау мүмкіндігін жоққа шығармайды.

Қорытындылар. Өткізілген тексерулер шала туылған балалардың қозғалыс жүйесіндегі клиникалық ерекшеліктерін алдын ала дамуын болжауға, оптимальді түрде медикаментті емес жолмен перинаталдық тарихы тарихы бар балалардың реабилитациясын жүргізуге ықпал етті.

Шала туылған балалардың клиникалық бағалау нәтижесінде, ПКВ 33 аптамен туылған баланың қоректендіргіш түтікте болған 70\% ы орта есеппен 6 күннен кейін кесемен пайдаланып азықтандыруға өтті және 40\% кесемен азықтандырылған балалардың 5-6 күннен кейін ана кеудесін емуге кіріскенін байқауға болады.

Барлық балаларда тұрақты салмақ қосу байқалды. Балалардың 80\% -ы тереңірек және тыныш ұйқыда болды. Ауырсыну манипуляциялары өткізілгенде, барлық балаларда ауырсынудың төменгі шегі бар болды. Мінез-құлықтың тұрақтылығы байқалды.

ПКВ 35 апталық балалардың 70\% өткізілген қызметтердің фонында кесемен азықтандырылған балалардың ана кеудесін емуге кіріскенін байқауға болады, басқа балалар - ана сүтімен қоректендірілді. Барлық нәрестелерде эмоционалдық тонус оң нәтиже берді. Базалық ынталандырудың арқасында көзбен концентрация жақсарды. Саусақтар мен алақандарға жасалған тактильді стимуляциялардың арқасында үлкен саусақты жұму мен жұдырық түю жақсарды және психомоторлық дамуын жақсартуға мүмкіндік берді.

Маңызды сөздер:шала туған нәресте, дене бітімі қозғалысы, Пехтла метод.

\section{PEЗЮME}

\section{АНАЛИЗ ДВИГАТЕЛЬНОЙ АКТИВНОСТИ У НЕДОНОШЕННЫХ НОВОРОЖДЕННЫХ}

Чувакова Т.К.',Тортаева Г.С. ${ }^{1}$, Сагандыкова Е.С. ${ }^{1}$

'Отдел неонатологии, Национальный научный центр материнства и детства корпоративного фонда «UMC», г. Астана, Казахстан

Цель исследования. Изучить клинические особенности двигательной системы недоношенных новорожденных, определить возможный прогноз развития и оптимизировать программу немедикаментозной реабилитации детей, родившихся с отягощенным перинатальным анамнезом.

Методы. Наблюдение за движениями ребенка велось с помощью видеокамеры, которую устанавливали над кувезом или кроваткой. Видеозапись движений ребенка проводилась в состоянии спокойного бодрствования, при отсутствии внешних раздражителей. Запись прерывалась на период кормления, сна, плача. Для съемки и оценки движений преждевременно родившегося младенца требуется сеанс видеозаписи длительностью 30-40 минут.

Результаты. По результатам обследования 129 недоношенных детей, проведенного в отделении неонатологии ННЦМиД, выявлено, что у детей с гестационным возрастом 29-34 недели наиболее часто встречается бедный репертуар - в 41,4\%. Нормальные генерализованные движения и вариант нормы - неоптимальные движения встречаются 22,7\% и 23,5\% соответственно, судорожно-синхронизированные и хоатические движения - у 12,9\%. При повторных исследованиях переходы: из нормальных генерализованных движений в бедный репертуар встречались у $3,2 \%$ детей, из бедного репертуара в нормальные генерализованные движения у 7,4\%, из судорожно-синхронизированных в бедный репертуар - у 1,6\%, из судорожно-синхронизированных в нормальные генерализованные движения - $11,9 \%$.В возрасте 3-5 месяцев жизни у всех детей с бедным репертуаром сформировался нормальный тип движений, а из 40 детей с судорожно-синхронизированными и хаотичными движениями, у 5 (1,6\%) диагностирован тетрапарез, что не исключает в последующем реализацию у этих детей ДЦП.

Выводы. Проведенноеисследование клинических особенностей двигательной системы недоношенных новорожденных определиловозможный прогноз развития, что способствовалопроведению оптимизированой программы немедикаментозной реабилитации детей, родившихся с отягощенным перинатальным анамнезом.

Клиническая оценка недоношенных детей по результатам развивающего ухода показала, что в ПКВ 33 недели, $70 \%$ детей, находившихся на зондовом кормлении в среднем через 6 дней переходили на вскармливание с помощью чашки и 40\% детей, уже кормившиеся из чашки - на 5-6-е сутки стали сосать материнскую грудь.

У всех детей отмечалась стабильная весовая прибавка. 80\% детей имели более глубокий и спокойный сон. При проведении болезненных манипуляций у всех детей установлен более низкий болевой порог. Наблюдалась стабилизация поведения.

В 35 недель ПКВ на фоне проводимых мероприятий 70\% детей перешли с кормления из чашки на грудное, остальные дети - находились на грудном вскармливании, Все дети были переведены на выхаживание в условиях кроватки. У всех младенцев отмечен положительный эмоциональный тонус. На фоне проведения базальной стимуляции улучшилось зрительное сосредоточение. Тактильная стимуляция ладоней и пальчиков позволила сформировать правильную установку большого пальца в кулачке и улучшить их психомоторное развитие.

Ключевые слова: недоношенные дети, двигательная активность, метод Прехтла.

\section{Введение}

В настоящее время не теряет своей актуальности проблема перинатальных поражениймозга у новорожденных детей. Именно перинатальная патология нервной системы у детей, частота которой составляет до $80 \%$ всех заболеваний центральной нервной системы (ЦНС) в детском возрасте [1], находится в центре внимания научной и практической медицины. Медико-социальная значимость проблемы состоит в том, что наиболее частой ее причиной является перинатальная гипоксия и асфиксия при рождении, вносящие существенный вклад в нарушения внутриутробного развития, в перинатальную смертность и, что особенно важно, определяет неврологическое здоровье и инвалидность с детства [2]. Это связано с тем, что перенесенная ребенком перинатальная гипоксия всегда оставляет свои следы в ЦНС в виде так называемых «молчаливых инфарктов», которые могут внезапно себя проявлять при разных провоцирующих состояниях (гипертермия, инфекция, повышенная умственная нагрузка и др.) $[3,4]$. 
Среди клинических проявлений перинатальной гипоксии и асфиксии при рождении самым распространенным и неоднозначным является синдром двигательных нарушений, который проявляется изменением мышечного тонуса и спонтанной двигательной активности, нарушением краниальной иннервации, а также угнетением рефлексов. Мышечный тонус новорожденного ребенка является одним из важных критериев не только состояния нервной системы, но и общего состояния ребенка.На изменения мышечного тонуса могут влиять различные факторы, в этой связи необходимо помнить о девиантных или транзиторных отклонениях в неврологическом статусе младенца, особенно в первые три месяца жизни, когда у ребенка наблюдается физиологическая гипертония.

В странах Западной Европы для оценки спонтанной двигательной активности детей применяется метод Прехтла (H.F.R.Prechtl). H.F.Prechtl в своей нейроэволюционной концепции считает, что спонтанная двигательная активность имеет эндогенный или центральный паттерн-генератор (central pattern generator) [5]. Исходя из этой концепции, движения, характерные для плода и ребенка раннего возраста - генерализованные движения, вздрагивания, потягивания, зевание, существуют вне зависимости от внешних факторов и развиваются под влиянием центрального паттерн-генератора. Генерализованные движения являются удобным объектом для исследования в связи с их частой встречаемостью, заметной длительностью (минуты) и вовлекаемостью мышц всего тела.

H.F.R.Prechtl [6] дифференцирует двигательную активность по типу (тоническая или физическая), a также по распространенности (общая или изолированная). В качестве примера тонического типа активности можно привести вздрагивание, а изолированного типа - подергивания. К общей фазической двигательной активности у младенцев относятся генерализованные движения, а изолированной - отдельные движения конечностей.

В чем же уникальность этого метода?

1. Обследование проводится в абсолютно естественных условиях, в отсутствии каких-либо внешних воздействий (зрительных, звуковых, тактильных).

2. Оцениваются не рефлексы, а свободные движения ребенка, сроки формирования которых тоже стандартны.

3. Метод позволяет выявлять изменения на более ранних этапах и более точно, чем при стандартном осмотре (при стандартном осмотре оцениваются рефлексы - то есть определенный ответ на воздействие).

4. Метод позволяет прогнозировать наличие или отсутствие отклонений, а не констатировать уже имеющиеся проблемы.

5.Высокая прогностическая ценность - 96\%, в то время как при стандартном наблюдении прогностическая ценность составляет только 30-40\%.

\section{Цель исследования}

Изучить клиническиеособенности двигательной системы недоношенных новорожденных, определить возможный прогноз развития и оптимизировать программу немедикаментозной реабилитации детей, родившихся с отягощенным перинатальным анамнезом.

\section{Материал и методы исследования.}

Под наблюдением было 129 недоношенных детей с гестационным возрастом от 29 до 34 недель. Наблюдение за движениями ребенка велось спомощью видеокамеры, которую устанавливали над кувезом или кроваткой. Видеозапись движений ребенка проводилась в состоянии спокойного бодрствования, при отсутствии внешних раздражителей. Запись прерывалась на период кормления, сна, плача. Для съемки и оценки движений преждевременно родившегося младенца требуется сеанс видеозаписи длительностью 30-40 минут.

Далее проводилась оценка полученных результатов наличие или отсутствие различных типов генерализованных движений, которые формируются постепенно, к определенным возрастным периодам. Результаты анализа фиксировались в карте, разработанной К. Эйнспилер, П. Б.Маршик и Я. Накаджима, 2004\2008г)(табл.1).

Для любого возраста есть своя норма спонтанных движений, и Прехтл создал специальные шкалы, позволяющие отделить норму от патологии. Видеозаписи следует делать каждые две-три недели с заполнением индивидуальной карты развития ребенка.

В норме ребенок двигает всеми четырьмя конечностями иодновременно ерзает, что означает: он здоров, сыт, спокоен. Формирование нормального типа двигательной активности происходит в 3-5 месяцев постконцептуального возраста (ПКВ -гестационный возраст + длительность постнатального периода), который назван «суетливостью» (fidgety) и представляет собой множественные быстрые движения шеи, головы, плеча, туловища, бедра, пальцев кисти, стопы, особое внимание уделяется контакту «рука - лицо», «рука - рука», «нога - нога». Выявление судорожно-синхронных движений рук и ног в 2-4 месяца ПКВ отражают ранние проявления тетрапареза. Значительное обеднение спонтанных движений рук и ног (бедный репертуар) на одной стороне в 2-3 месяца ПКВ может в последующем проявиться спастическим гемипарезом. Маркерами спастических и дискинетических форм ДЦП в 3-5 месяцев ПКВ является отсутствие подъема ног в положении лежа на спине, отсутствие суетливых движений (fidgety).

Таблища 1 Оценка движений младенца.(КристаЭйнспилер, Питер Б.Маршик и ЯйохиНакаджима, 2004\2008г)

Имя

Состояние/сопутствующие состояия:

Постконцептуальный возраст

Дата записи

Глобальная оценка.

\begin{tabular}{|l|l|l|l|l|l|}
\hline & - & норма & Последовательность & & \\
\hline & - & 2-разнообразные,сложные & & & \\
\hline & - & Норма,неоптимальная & & 1-прерывистые(некоторые части \\
не вовлечены)
\end{tabular}


Детальная оценка движений туловища и шеи.

\begin{tabular}{|c|c|c|c|c|c|c|}
\hline & шея & & & туловище & & \\
\hline \multicolumn{7}{|c|}{ Ротационный } \\
\hline \multirow[t]{3}{*}{ комплекс } & Вовлечен в последовательность & - & 2 & Присутствует, плавные и элегантные & - & 2 \\
\hline & $\begin{array}{l}\text { Едва присутствует, ек вовлечен в } \\
\text { процесс }\end{array}$ & - & 1 & Несколько ротаций & - & 1 \\
\hline & & & & Практически без ротации & - & 0 \\
\hline
\end{tabular}

\section{Детальная оценка движений в конечностях}

\begin{tabular}{|c|c|c|c|c|c|c|}
\hline & Верхняя конечность & & & Нижняя конечность & & \\
\hline \multirow[t]{4}{*}{ амплитуда } & Разнообразные в полном объеме & - & 2 & Разнообразные в полном объеме & - & 2 \\
\hline & В основном небольшая & - & 1 & В основном небольшая & - & 1 \\
\hline & В основном большая & - & 1 & В основном большая & - & 1 \\
\hline & В основном одной амплитуды & - & 1 & В основном одной амплитуды & - & 1 \\
\hline \multirow[t]{4}{*}{ скорость } & разнообразная & - & 2 & разнообразная & - & 2 \\
\hline & В основном маленькая & - & 1 & В основном маленькая & - & 1 \\
\hline & В основном большая & - & 1 & В основном большая & - & 1 \\
\hline & В основном одной скорости & - & 1 & В основном одной скорости & - & 1 \\
\hline \multirow[t]{3}{*}{ пространство } & В разных направлениях & - & 2 & В разных направлениях & - & 2 \\
\hline & ограниченное & - & 1 & ограниченное & - & 1 \\
\hline & Только в одной плоскости & - & 0 & Только в одной плоскости & - & 0 \\
\hline \multirow{3}{*}{$\begin{array}{l}\text { Проксимальный } \\
\text { ротаторный } \\
\text { компонент }\end{array}$} & $\begin{array}{l}\text { Присутствует,плавный и элегант- } \\
\text { ный }\end{array}$ & - & 2 & Присутствует,плавный и элегантный & - & 2 \\
\hline & Только несколько ротаций & - & 1 & Только несколько ротаций & - & 1 \\
\hline & Практический без ротации & - & 0 & Практический без ротации & - & 0 \\
\hline \multirow[t]{2}{*}{ начало } & плавное & - & 2 & плавное & - & 2 \\
\hline & С минимальными & & & & & \\
\hline флюктуациями & - & 1 & С минимальными & & & \\
\hline \multirow[t]{2}{*}{ флюктуациями } & - & 1 & & & & \\
\hline & внезапное & - & 0 & внезапное & - & 0 \\
\hline \multirow[t]{2}{*}{ конец } & плавное & - & 2 & плавное & - & 2 \\
\hline & С минимальными & & & & & \\
\hline флюктуациями & - & 1 & С минимальными & & & \\
\hline \multirow[t]{2}{*}{ флюктуациями } & - & 1 & & & & \\
\hline & Внезапное завершение & - & 0 & Внезапное завершение & - & 0 \\
\hline \multirow{3}{*}{$\begin{array}{l}\text { Дрожащие } \\
\text { движения }\end{array}$} & отсутсвует & - & 2 & отсутсвует & - & 2 \\
\hline & Присутствует с одной стороны & - & 1 & Присутствует с одной стороны & - & 1 \\
\hline & Присутсвует с двух сторон & - & 0 & Присутсвует с двух сторон & - & 0 \\
\hline \multirow{3}{*}{$\begin{array}{l}\text { Судорожный } \\
\text { компонент }\end{array}$} & отсутсвует & - & 2 & отсутсвует & - & 2 \\
\hline & Присутствует время от времени & - & 1 & Присутствует время от времени & - & 1 \\
\hline & В основном присутсвует & - & 0 & В основном присутсвует & - & 0 \\
\hline \multirow[t]{2}{*}{$\begin{array}{l}\text { Оптимальная } \\
\text { оценка }\end{array}$} & Верхние конечности(макс.18) & & $\begin{array}{l}\text { Нижние конечности } \\
\text { (макс.18) }\end{array}$ & & & \\
\hline & Туловище и шея(макс.4) & & $\begin{array}{l}\text { Последовательность } \\
\text { (макс.2) }\end{array}$ & & & \\
\hline
\end{tabular}

Оптимальная оценка для генерализованных движений составляет 42 балла.

\section{Результаты}

По результатам обследования 129 недоношенных детей, проведенного в отделении неонатологии ННЦМиД, выявлено, что у детей с гестационным возрастом 29-34 недели наиболее часто встречается бедный репертуар - в $41,4 \%$. Нормальные генерализованные движения и вариант нормы - неоптимальные движения встречаются 22,7\% и $23,5 \%$ соответственно, судорожно-синхронизированные и хоатические движения - у 12,9\%.

При повторных исследованиях переходы: из нормальных генерализованных движений в бедный репертуар встречались у $3,2 \%$ детей, из бедного репертуара в нормальные генерализованные движения у 7,4\%, из судорожно-синхронизированных в бедный репертуар - у $1,6 \%$, из судорожно-синхронизированных в нормальные генерализованные движения - у1,9\%.

В возрасте 3-5 месяцев жизни у всех детей с бедным репертуаром сформировался нормальный тип движений, а из 40 детей с судорожно-синхронизированными и хаотичными движениями, у $5(1,6 \%)$ диагностирован тетрапарез, что не исключает в последующем реализацию у этих детей ДЦП. 


\section{Обсуждение.}

Проведенное исследование показало значимую диагностическую ценность оценки генерализованных движений у новорожденных в прогнозе развития неврологических нарушений. Полученные результаты обосновали необходимость начала восстановительного лечения уже с первых дней-недель жизни, а именно проведение развивающего ухода, который включал: создание комфортных условий жизни, индивидуальную программу развития.

Создание комфортных условий жизни, как основы нормальной жизни младенца, подразумевало организацию лечебно-охранительного режима, адекватного питания младенца, поддержание инфекционной безопасности. Лечебноохранительный режим представлял свето- и шумоизоляцию, температурный контроль, ограничение тактильных воздействий, профилактику боли, специальные укладки, способствующие комфортному положению ребенка, соблюдение стандартов выполнения манипуляций и круглосуточное присутствие матери.

В индивидуальную программу развития входили два взаимо-содружественных начала: физические методы реабилитации и психоэмоциональное воздействие.Методы психоэмоционального воздействия включали: общение мамы с ребенком - «мама-терапия», метод «кенгуру», базальная стимуляция и музыкотерапия.Физические методы реабилитациивключали тактильную стимуляцию ладоней и пальцев, лечение положением, массаж, лечебную физкультуру. Все это подразумевает немедикаментозную реабилитацию новорожденного.

При проведении дозированной индивидуальной программы разрабатывалась дозированная индивидуальная программа со своевременной ее коррекцией учетом результатов наблюдения за проводимой методикой, реакцией ребенка и медикаментозной терапии. Частота проведения дозированной индивидуальной программы- 2-3 раза в день, курс 3 недели-1 месяц, затем перерыв на 2 недели.

Результаты проведения развивающего ухода (немедикаментозной реабилитации)оценивались по весовой кривой, времени перехода ребенка с зондового питания на альтернативные методы вскармливания (с помощью чашки, шприца) и на самостоятельное сосание груди, поведение, реакция на внешние раздражители, в том числе на болезненные манипуляции, сон, двигательные реакции.

\section{Выводы.}

Клиническая оценка недоношенных детей по результатам развивающего ухода показала, что в ПКВ 33 недели, $70 \%$ детей, находившихся на зондовом кормлении в среднем через 6 дней переходили на вскармливание с помощью чашки и 40\%детей, уже кормившиеся из чашки - на 5-6-е сутки стали сосать материнскую грудь. У всех детей отмечалась стабильная весовая прибавка. 80\% детей имели более глубокий и спокойный сон. При проведении болезненных манипуляций у всех детей установлен более низкий болевой порог. Кроме того, наблюдалась стабилизация поведения.

В 35 недель ПКВ на фоне проводимых мероприятий 70\% детей перешли с кормления из чашки на грудное, остальные дети - находились на грудном вскармливании, Все дети были переведены на выхаживание в условиях кроватки. У всех младенцев отмечен положительный эмоциональный тонус. На фоне проведения базальной стимуляции улучшилось зрительное сосредоточение. Тактильная стимуляция ладоней и пальчиков позволила сформировать правильную установку большого пальца в кулачке и улучшить их психомоторное развитие.

\section{Литература}

1. PalchikA.B., SchabalovN.P. Hipoksicheski-ischemicheskaya encephalopatiya u novorodjennih (Hypoxic-ischemic encephalopathy in newborns) [in Russian].MEDPRESSinform. 2009; 253.

2. OrelV.I.,KuznetcovaE.U., KakabadzeI.T.,Materiali IV siyezda Rossiyskoiy associacii specialistov perinatalnoiy medicine (Materials of the IV Congress of the Russian Association of Specialists in Perinatal Medicine)[in Russian]. 2002; 315 : 61.

3. Baraschnev U.I. Hipoksicheskaya encephalopatiya: hypotezipatogenez acerebralnih passtroistv I poisk metodov lekarctvennoi terapii. Rossiyskiy vestnik perinatologii I pediatrii (Hypoxic encephalopathy: a hypothesis of the pathogenesis of cerebral pasts. Look for methods of drug therapy. The Russian herald of perinatology and pediatrics.) [in Russian]. 2002; 1:6-13.

4. Baraschnev U.I.,Rozanov A.V., Panov V.O., Volobuev A.I. Rol hipoksicheski-travmaticheskogo povrejdenia golovnogo mozga v

5. formirovanii invalidnosti s detstva. Rossiyskiyvestnikperinatologii I pediatrii(The role of hypoxic-traumatic subordination of the brain in the disability formation since childhood.Russian herald of perinatology and pediatrics)[in Russian]. 2006; 4: 41-47.

6. Prechtl H.F.R.The optimality concept.1980; 4; 3:201-205.

7. Prechtl H.F.R. Early prediction of later neurological deficits /H.F.R. Prechtl,

8. C.Einspieler. Longitudinal studies in children at risk. Satellite Meeting of the

9. 8Internat. Neurology Congress in Ljubljana. Vienn: 1998; 56. 